\title{
WPS3563
}

\section{Health Insurance Impacts on Health and Nonmedical Consumption in a Developing Country}

\author{
Adam Wagstaff \\ Development Research Group and East Asia Human Development Unit \\ The World Bank, Washington DC, USA \\ Menno Pradhan \\ Indonesia Resident Mission \\ The World Bank, Jakarta, Indonesia
}

World Bank Policy Research Working Paper 3563, April 2005

The Policy Research Working Paper Series disseminates the findings of work in progress to encourage the exchange of ideas about development issues. An objective of the series is to get the findings out quickly, even if the presentations are less than fully polished. The papers carry the names of the authors and should be cited accordingly. The findings, interpretations, and conclusions expressed in this paper are entirely those of the authors. They do not necessarily represent the view of the World Bank, its Executive Directors, or the countries they represent. Policy Research Working Papers are available online at http://econ.worldbank.org.

Corresponding author and contact details: Adam Wagstaff, The World Bank, $1818 \mathrm{H}$ Street NW, Washington, D.C. 20433, USA. Tel. (202) 473-0566. Fax (202)-522-1153. Email: awagstaff@worldbank.org.

Acknowledgements: We are grateful for comments on an earlier version to Martin Ravallion and to participants at the International Health Economics Association Meeting in San Francisco in 2003, and faculty and students at Tinbergen University. 


\section{Summary}

We examine the effects of the introduction of Vietnam's health insurance (VHI) program on health outcomes, health care utilization, and nonmedical household consumption. The use of panel data collected before and after the insurance program's introduction allows us to eliminate any confounding effects due to selection on time-invariant unobservables, and our coupling of propensity score matching with a double-difference estimator allows us to reduce the risk of biases due to inappropriate specification of the outcome regression model. Our results suggest that Vietnam's health insurance program impacted favorably on height-for-age and weight-for-age of young school children, and on body mass index among adults. Our results suggest that among young children, VHI increases use of primary care facilities, and leads to a substitution away from the use of pharmacists as a source of advice and non-prescribed medicines toward the use of them as a supplier of medicines prescribed by a health professional. Among older children and adults, VHI results in a marked increase in the use of hospital inpatient and outpatient departments. Our results also suggest that VHI causes a reduction in annual out-of-pocket expenditures on health, and an increase in nonmedical household consumption, including food consumption but mostly non-food consumption. Our estimate of the VHI-induced reduction in out-of-pocket health spending is considerably smaller than our estimate of the VHI-induced increase in nonmedical consumption, which is consistent with the idea that households hold back their household consumption considerably if, through lack of health insurance, they are exposed to the risk of large out-of-pocket expenditures. This is especially plausible in a country where at the time (1993), a single visit to a public hospital cost on average the equivalent of $20 \%$ of a person's annual non-food consumption.

Keywords: Health insurance; impact evaluation.

JEL codes: $\mathrm{I} 1, \mathrm{O} 1$ 


\section{INTRODUCTION}

Policy toward health insurance requires striking a balance between the benefits insurance brings and the costs and inefficiencies involved (cf. e.g. Arrow 1963, Feldstein 1973, Manning and Marquis 1996). Until recently, most of the empirical literature on health insurance was focused on the latter, and in particular on the market inefficiencies arising from information asymmetries between the insured and insurer, especially the issue of moral hazard. Recently, the literature has shifted focus somewhat toward the benefits of health insurance, and has had some second thoughts about the methods used hitherto to investigate moral hazard.

Several recent studies investigate the benefits of health insurance in terms of improved health outcomes. ${ }^{1}$ These include three recent studies of the expansion of Medicaid in the US, exploiting for identification purposes the fact that some states expanded eligibility more than others did and at different times (Currie and Gruber 1996b, Currie and Gruber 1996a, Currie and Gruber 1997). Currie and Gruber (1996a) find that Medicaid expansion significantly increased use of services among children and significantly reduced child mortality. Significant effects on low birthweight and infant mortality were found in another paper (Currie and Gruber 1996b), while in their third paper Currie and Gruber (1997) found that impacts on infant mortality were larger for mothers and infants living close to high-tech hospitals. Hanratty (1996) reports significant impacts on infant mortality of Canada's health insurance program, the analysis again taking advantage of variations in the date of adoption of health insurance across geographic units (in this case provinces).

In addition to the benefits in terms of better health, several other studies examine the issue of how far health insurance, through reducing uncertainty, enables households to reduce precautionary savings and labor supply. Gruber and Yelowitz (1999) find that Medicaid in the US led to a reduction in savings and an increase in consumption. Chou et al. (2003) find that the introduction of National Health Insurance (NHI) in Taiwan led to a reduction in precautionary savings and to an increase in consumption, while Chou and Staiger (2001) found Taiwan's NHI led to a reduction in female labor force participation. The welfare implications of such findings are, of course, not straightforward: the case needs to be made - though it is surely a plausible one- that informal insurance devices, such as precautionary savings and diversification in household labor supply choices, are less efficient than formal health insurance.

In a largely parallel literature, reservations have been expressed (cf. e.g. Cutler and Zeckhauser 2000, Vera-Hernandez 2003) about the tendency in the literature to equate moral hazard to the effect of insurance on medical care utilization. ${ }^{2}$ Moral hazard, it noted, reflects an information asymmetry between the insured and insurer, and the fact that the parties cannot contract over an unobserved variable. To the extent that the insurer can infer the value of the unobservable variable from observable contractible variables, the problem of moral hazard diminishes, and at the limit disappears altogether. The degree to which this happens is independent of the elasticity of use with respect to insurance coverage. Indeed, the increased

\footnotetext{
${ }^{1}$ See Levy and Meltzer (2001) for a very useful review of this literature.

2 Examples of recent studies in this genre include Waters (1999), Harmon and Nolan (2001), Sapelli and Vial (2003), Trujillo (2003), Jowett et al. (2003) and Savage and Wright (Jowett et al. 2003).
} 
utilization that greater coverage permits is one of the factors that motivates health insurance, and is likely to account for a potentially large fraction of the welfare gain associated with it (cf. Nyman 1999). Insurance affords the prospect of receiving treatment that would have been beyond the feasible set in the absence of insurance. Further, linked to the other strand of literature discussed above, insurance reduces uncertainty and produces a wealth effect, which is likely to translate into higher levels of medical care use irrespective of whether there is any moral hazard at work (cf. de Meza 1983).

If the risk-reduction attributable to health insurance is associated with wealth effects in medical care utilization, it is also likely to be associated with wealth effects in the consumption of other commodities, some of which may be beneficial to health. If a household knows that by acquiring health insurance it has reduced its exposure to the risk of large out-of-pocket health expenses, it is likely to 'spend' some of this extra wealth on food, shelter, clothes, housing, education and other items of the household budget. In poor households, this extra spending may well be one of the channels by which health insurance leads to better health outcomes. Evidence from rural China, where health insurance coverage dropped dramatically following the decollectivization of agriculture, suggests that the risk associated with medical expenses does indeed influence a variety of household decisions, including the amount of wealth households hold, the share of wealth they hold in liquid form, the extent of temporary migration and school enrollment (Jalan and Ravallion 2001).

This paper estimates the impacts of health insurance on health outcomes, and on other variables some of which may conceivably impact on health outcomes, such as the use of medical care, food consumption, spending on water, and the use value associated with household durables. The setting is Vietnam in the 1990s. Vietnam's social health insurance program, or Vietnam Health Insurance (VHI) as it was known at the time, was set up in 1993 in response to a growing concern over the scale of out-of-pocket payments for health. In 1993, over 70\% of health spending in Vietnam was paid out-of-pocket, and out-of-pocket payments absorbed 6\% of the average household's total consumption (World Bank et al. 2001, Wagstaff 2002). As many as $18 \%$ of households spent more than $10 \%$ of their total consumption on health care, and as many as $47 \%$ of households spent more than $10 \%$ of their non-food consumption on health care (Wagstaff and van Doorslaer 2003). In 1993, a single visit to a public hospital by someone from the bottom quintile cost the equivalent of $41 \%$ of their annual non-food consumption (World Bank et al. 2001). Unsurprisingly, health care payments were a major source of concern among Vietnamese participants in the global participatory poverty study Voices of the Poor (Narayan et al. 2000).

Given this background, and given its very generous initial coverage (copayments were introduced only in late 1998), VHI can reasonably be expected to have had effects on both medical care use and on the consumption of other budget items, with likely consequences for health outcomes. We estimate insurance impacts through the use of propensity score matching (PSM) on longitudinal data collected just before the introduction of VHI in 1992/93 and five years later in 1997/98. ${ }^{3}$ Two-thirds of those joining VHI in this period-and $95 \%$ of adults

\footnotetext{
3 The use of PSM and longitudinal data are two features that distinguish the present study from that of Trivedi (2003), who used regression analysis on the 1997/98 cross-section data. The present study also looks beyond health care use and health care spending. There are also differences in variable definitions that further make comparisons rather difficult. For example, Trivedi defines annual health spending as the sum of spending in the last 4 weeks and spending in the last 12 months, whereas we treat them as two separate variables, assuming that one measures spending in the last month and the other spending in the last year.
} 
joining the scheme-were compulsorily enrolled by virtue of their employment with the government or a state-owned enterprise, or being a pensioner or a 'person of merit' (such as a war veteran). The bulk (95\%) of those voluntarily enrolled were school children, whose schools are encouraged to enroll their pupils by the local Communist party. While there appears to have been very little self-selection into the scheme during this period, there is the possibility that those selected into the scheme share unobservable attributes that make them healthier (or heavier users of health care) than those not selected. The pre-post longitudinal data allow us to replace the standard PSM assumption - that outcomes are independent of participation given the values of the relevant pre-intervention control variables - by a weaker assumption, namely that changes in outcomes are independent of participation given the pre-intervention controls (cf. Blundell and Costa Dias 2000). We are thus able to eliminate any bias due to time-invariant unobservable heterogeneity, in addition to bias due to observable heterogeneity which PSM on cross-section data already eliminates (cf. Heckman, Ichimura and Todd 1997, Heckman et al. 1998, Jalan and Ravallion 2003a). We are, however, forced to assume that any unobserved time trend in our outcomes is the same for the insured and uninsured. Only randomization can completely rule out such a possibility, which in principle is a concern even in studies that exploit differences in speed of adoption across geographic units. The attraction of PSM over a regression analysis is that we do not need to specify any model for our outcomes and hence reduce the risk of biases due to inappropriate model specification, whether in the functional form or the covariates included. We do have to do some modeling, namely in the prediction of propensity scores - the probability of being enrolled in VHI.

Section II outlines the salient features of Vietnam's health insurance program. Section III sets out our estimation method, based on a combination of propensity score matching and double differencing on pre-intervention and post-intervention data. Section IV outlines the model used to generate our propensity scores, and compares the distributions of the propensity scores of the insured and uninsured pre- and post-matching. Sections V-VIII contain our results for health outcomes, health utilization, out-of-pocket expenditures and nonmedical consumption, respectively. Section IX contains our conclusions.

\section{VIETNAM'S HEALTH INSURANCE PROGRAM}

Prior to the Doi Moi (or 'renovation') reforms of the late 1980s, health services in Vietnam were provided at the taxpayer's expense, with patients paying only the cost of drugs (Bloom 1998). The decollectivization of agriculture and the liberalization of the economy led to a swift erosion of the government's role in financing health care in Vietnam. Following changes in 1989 government facilities were allowed to charge fees, and in 1991 legislation was passed that paved the way for a private health sector (Bloom 1998, Glewwe 2003). The share of the cost of health care borne directly by households is likely to have increased considerably following these reforms. This prompted concerns about the affordability of health care, especially among the poor, which in 1993 still accounted for $58 \%$ of the population (Glewwe 2003). Subsequent analysis of data from the 1993 Vietnam Living Standards Survey (VLSS) bore these concerns out: a single visit in 1993 to a public hospital by someone from the bottom quintile would have cost the equivalent of $41 \%$ of their annual non-food consumption (World Bank et al. 2001). Even for the population as a whole, the figure was close to $20 \%$. 
It was against this background that in 1993 the government introduced a health insurance scheme, known initially as Vietnam Health Insurance (VHI). Civil servants, state enterprise workers, the military, Communist party officials and pensioners who were previously in one of these government jobs were (and continue to be) covered, and private firms with more than 10 employees were (and still are) required to enroll their workers. Table 1 gives a breakdown across the categories for 1998, the first year for which a full breakdown is possible. The contribution for compulsory workers is split between the worker and the employer, and the coverage is generous: the fees for inpatient and outpatient care are covered, as are the costs of drugs used in inpatient care (World Bank et al. 2001); prior to 1998 (the year of the follow-up survey used in the analysis below), no copayments were required. A voluntary component of the VHI program also exists, aimed at the rest of the population. However, in practice the scheme has succeeded only in enrolling students, who account for $92 \%$ of the voluntarily insured (see Table 1). Schools are pressured by local governments to enroll their students, and the schools in turn pressure parents, who pay the contribution (World Bank et al. 2001). The proportion of students covered varies considerably across provinces (Government of Vietnam 2002b), presumably reflecting the varying pressure applied by different local governments. Coverage is much less generous for the voluntarily enrolled, including typically only inpatient benefits. However, students who are enrolled in VHI can obtain care at a school clinic which VHI helps large schools establish.

Table 1: Breakdown of insureds in Vietnam's health insurance (VHI) scheme, 1998

\begin{tabular}{|c|c|c|c|}
\hline & \multicolumn{3}{|c|}{ \# people $\%$ population $\%$ insureds $\%$ group } \\
\hline Population & $77,046,000$ & & \\
\hline $\begin{array}{l}\text { VHI insureds } \\
\text { of which }\end{array}$ & $9,758,015$ & $12.7 \%$ & \\
\hline $\begin{array}{l}\text { Compulsory } \\
\text { of which }\end{array}$ & $6,069,309$ & $7.9 \%$ & $62.2 \%$ \\
\hline Civil servants & $1,367,768$ & & $22.5 \%$ \\
\hline State enterprises & $1,561,710$ & & $25.7 \%$ \\
\hline Private enterprises & 310,757 & & $5.1 \%$ \\
\hline Pensioners & $1,179,102$ & & $19.4 \%$ \\
\hline People of merit & $1,212,048$ & & $20.0 \%$ \\
\hline Commune administration staff & 37,924 & & $0.6 \%$ \\
\hline $\begin{array}{l}\text { Voluntary } \\
\text { of which }\end{array}$ & $3,688,706$ & $4.8 \%$ & $37.8 \%$ \\
\hline Students & $3,402,328$ & & $92.2 \%$ \\
\hline
\end{tabular}




\section{METHODS}

In the panel dataset we use-the Vietnam Living Standards Survey (VLSS) ${ }^{4}$-we observe most of the outcomes of interest during the first wave (fielded in 1992/93 just before the introduction of VHI), and again in the second wave (fielded in 1997/98). In what follows, $t=1$ denotes 1992/93 and $t=2$ denotes 1997/98.

Let $y_{i t}$ be the outcome of interest for individual $i$ at time $t$. In our empirical analysis $y$ alternates between health status, out-of-pocket payments, nonmedical consumption and utilization of health services. We assume that the change in $y_{i t}$ between 1993 and 1998 in the case of the "treated" group (i.e. those enrolled in VHI after it was introduced) can be written":

$$
\Delta y_{i t}^{T}=\Delta y_{i t}^{*}+\Delta G_{i t}+\Delta \theta_{t}+\Delta \varepsilon_{i t}
$$

where $\Delta$ denotes the change between 1993 and 1998, $y_{i t}^{*}$ is the counterfactual outcome for VHI enrollees, $G_{i t}$ is the "gain" or impact of the program, $\theta_{t}$ is unobserved and specific to period $t, \varepsilon_{i t}$ is a white noise measurement error term associated with the outcome variable, and $N$ is the number of individuals who were enrolled in VHI in period 2. For each participant (i.e. insured), we use propensity score matching (PSM) to identify a matched non-participant (cf. Rosenbaum and Rubin 1983). ${ }^{6}$ This involves estimating regression (e.g. probit) equations for the participation decision, and defining a nearest neighbor for each participant as the non-participant with the closest propensity score (predicted participation probability). We assume that for the $N$ matched controls we can write:

$$
\Delta y_{i t}^{M}=\Delta y_{i t}^{*}+\Delta \theta_{t}+\Delta u_{i t}
$$

where $u_{i t}$ is a white-noise error term. Subtracting eqn (2) from eqn (1) gives the doubledifference or difference-in-differences:

$$
\Delta y_{i t}^{T}-\Delta y_{i t}^{M}=\Delta G_{i t}+\Delta \varepsilon_{i t}-\Delta u_{i t}
$$

which, given $G_{i 1}=0$ (the program did not exist at $t=1$ ), can be rewritten:

$$
\Delta y_{i t}^{T}-\Delta y_{i t}^{M}=G_{i 2}+\Delta \varepsilon_{i t}-\Delta u_{i t} .
$$

Taking expectations of eqn (3') gives

$$
E\left[\Delta y_{i t}^{T}-\Delta y_{i t}^{M}\right]=E\left[G_{i 2}\right]
$$

given $\varepsilon$ and $u$ are assumed to have zero mean.

\footnotetext{
${ }_{5}^{4}$ Further details on the survey can be found at http://www.worldbank.org/lsms/.

5 The notation and exposition in this section borrows heavily from Ravallion et al. (2003).

${ }^{6}$ Crystal clear expositions of PSM with economic applications are to be found in Jalan and Ravallion (2003a, 2003b). Blundell and Costa Dias (2000) provide a useful survey of evaluation methods, and show how PSM relates to other methods. Applications of PSM in the health sector include Newman et al. (2002), Pradhan and Rawlings (2002), Sadaah et al. (2001) and Jalan and Ravallion (2003a).
} 
Eqns (1) and (2) assume that conditional on the propensity score, participation in the insurance program is independent of the change in outcome between the year before the program was introduced and the date of the second wave of the survey, five years later. Eqns (1) and (2) are compatible with individual-specific time-invariant unobservables, so that our estimates will not be contaminated by any selection on time-invariant unobservables. We have also allowed for a common unobservable growth component in the outcome growth equations. Under our assumptions, the only driver of differential change between the insured and matched uninsureds is the fact that the former are insured and the latter are not. The risk we run is that the unobserved time trends are not - contrary to what we assume-independent of insurance status. If the insured have a more favorable time trend than the uninsured, we will end up attributing differences in changes in $y$ to insurance when they are, in fact, attributable — at least in part - to different unobserved time trends.

The link with standard exogeneity assumptions and the attractions of the matching approach can be seen as follows (cf. Imbens 2004). Suppose one were prepared to assume that the treatment effect is constant, and that the outcome among the uninsured is linear in $X_{i}$. With cross-section data one could try to recover the treatment effect from a regression of the outcome on an insurance status dummy $(I)$ and the vector $X_{i}$ :

$$
y_{i}=\alpha+\tau I_{i}+X_{i} \beta+\varepsilon_{i}
$$

Estimation might proceed on the assumption that $I$ is exogenous in the sense that conditional on $X, I$ and $\varepsilon$ are uncorrelated, which is the regression equivalent of the 'unconfoundedness' or 'ignorable treatment assignment' assumption made in the treatment effects literature when crosssection data are used. Or one might use a Heckman selection model and rely either on functional form or exclusion restrictions to identify the insurance effect. Both have been used in the insurance literature, but neither is altogether satisfactory. ${ }^{7}$

In the present context, with a two-wave panel conducted before and after the insurance scheme was introduced, we are able to make a much weaker exogeniety assumption (cf. Blundell and Costa Dias 2000). Instead of (5), the regression analogue of what we have is:

$$
y_{i 1}=\alpha+X_{i 1} \beta+\theta_{1}+\mu_{i}+\varepsilon_{i 1}
$$

and

$$
y_{i 2}=\alpha+\tau I_{i 2}+X_{i 2} \beta+\theta_{2}+\mu_{i}+\varepsilon_{i 2}
$$

so that if $\Delta$ denotes the difference between period $t=1$ and $t=2$, we get

\footnotetext{
${ }^{7}$ Studies relying on the non-linearity of the Heckman model to secure identification include the studies of Waters (1999) and Jowett et al. (2003). A number of studies explore exclusion restrictions to identify the effects of insurance in a cross-section context. Gertler and Strum (1997) consider various possibilities, but in the end conclude they have no plausible instruments. Harmon and Nolan (2001) exclude education from the utilization equation, which they acknowledge is problematic, and resort to non-linearity as the alternative identification strategy. Guariglia and Rossi (2004) in their analysis of the impact of health insurance on savings in the UK use as identifying instruments occupation, workplace size, whether the individual has an occupational pension, and whether he or she works in the private sector. It is not at all obvious why any of these ought to be excluded from the savings equation.
} 


$$
\Delta y_{i t}=\tau I_{i 2}+\Delta X_{i t} \beta+\Delta \theta_{t}+\Delta \varepsilon_{i t} .
$$

Our exogeneity assumption is equivalent in a regression context to assuming that, conditional on $X_{i t}$ (or rather its change), $I$ is independent of $\Delta \theta_{t}$ and $\Delta \varepsilon_{i t}$. This leaves open the possibility that the time-invariant individual-specific unobservable, $\mu_{i}$, is correlated with $I$, conditional on $\Delta X-$ i.e. that there is selection on time-invariant unobservables. The main risk being run is that it may not be the case that, conditional on the covariates, the period-specific unobservable, $\theta$, grows by the same amount for the insured and uninsured. This is a risk one will always run outside a randomized experiment. Whenever insurance cover is provided to or withdrawn from some people before others, there is always the possibility - unless the assignment is random - that, conditional on $\Delta X, \Delta \theta_{t}$ and $I$ are correlated.

The estimation approach has various attractions. In contrast to the regression approach, it does not require the specification of a model-let alone a parametric one-for our outcome variable. We do need to estimate a regression model to capture the enrollment decision, but in the case of VHI this is relatively straightforward especially for the compulsorily enrolled.

\section{ESTIMATION OF PROPENSITY SCORES}

Our first task is the estimation of the propensity scores which provide us with a basis for matching each enrolled individual with a suitable comparator from the non-enrolled subsample. For this we require an insurance coverage variable, as well as variables measured in 1992-93 that influence insurance enrollment.

The VLSS health module asks respondents whether they have insurance coverage. Workers are asked again in the main job module whether they receive health benefits from their employer and if so whether this takes the form of health insurance. In what follows, we classify an individual as insured with VHI if they answer Yes to either module's question. ${ }^{8}$ VHI coverage is estimated at around $17 \%$ for the sample as a whole (Table 2), somewhat higher than the official VHI figures for 1998. This discrepancy may be because some VLSS respondents with health insurance are insured with an organization other than VHI, the obvious one being Bao Viet, the insurance arm of Vietnam's Ministry of Finance, which provides insurance for shipping and heavy industry, but which also provides health insurance, mainly to school children. VHI coverage ranges from $27 \%$ in the richest consumption quintile to under $10 \%$ in the poorest, though there is considerable variation within each quintile. Coverage (in 1997/98) also varies with age (Figure 2), being relative high among those who were in the 6-15 age group in 1997/98, then dipping and picking up again among those in the 45-70 age group in 1997/98.

\footnotetext{
${ }^{8}$ An unsuccessful attempt was made to construct separate variables for compulsory and voluntary coverage within VHI.
} 
Table 2: VHI coverage by consumption quintile

\begin{tabular}{lccr}
\hline Quintile & Mean & Std. Dev. & \# cases \\
\hline & & & \\
1 & 0.0911 & 0.2878 & 3656 \\
2 & 0.1225 & 0.3279 & 3754 \\
3 & 0.1690 & 0.3748 & 3586 \\
4 & 0.2041 & 0.4031 & 3473 \\
5 & 0.2709 & 0.4445 & 3355 \\
Total & 0.1693 & 0.3750 & 17824 \\
& & & \\
\hline
\end{tabular}

Source: VLSS data.

Figure 2: Enrollment in 1997/98 by age in 1992/93

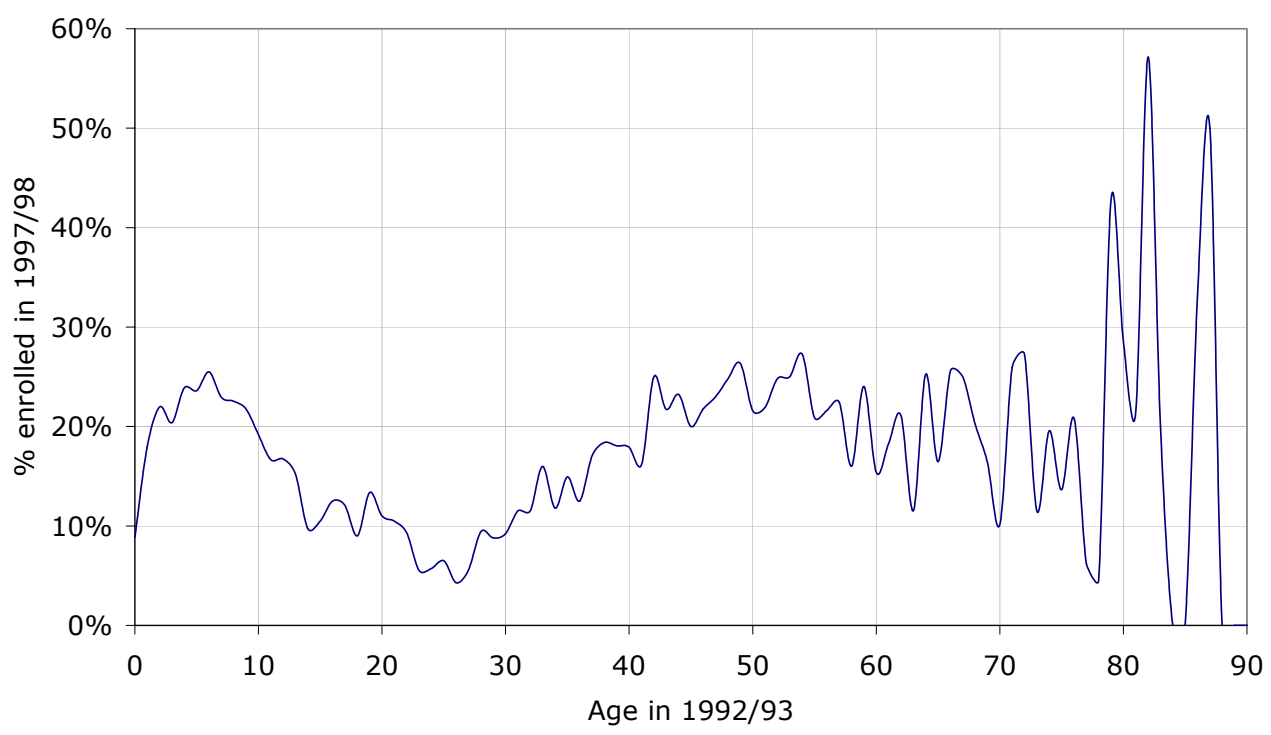

Source: VLSS data.

On the face of it, VHI enrollment ought to be almost perfectly predictable on the basis of employer type, pensioner status and schooling status. In the event, our probit enrollment equation (Table 3) gives a pseudo R-squared of only 0.19 , pointing to considerable variation across similar individuals in the probability of being enrolled. As expected, being in school (around 25\% of our sample is currently in school) has a significant positive effect on VHI enrollment. Age has no significant effect on enrollment, once being in school and pensioner status are controlled for. Unsurprisingly, too, a person's job has a marked impact on insurance status. The equation includes the employer of individuals with one or more formal sector jobs in the week prior to the VLSS interview. The omitted category from the employer dummies is "no employer". Very few individuals in the sample have formal sector jobs and even fewer have jobs in organizations providing VHI coverage under the compulsory scheme. As expected, the enrollment probability is higher for individuals having a job in the communist party, government or army, as well as for those having a main job in a state enterprise, social organization or a cooperative. Those with a main or second job in the private sector are significantly less likely to be enrolled in VHI. Being a pensioner increases the probability of enrollment. 
A variety of household-level variables are also included. The probability of enrollment increases with per capita household income. Enrollment is significantly higher among people living in a household where the head of household had completed at least lower secondary education. Enrollment increases with grade completed above this level.

Rather than including community-level variables per se, the enrollment equation includes fixed effects measured at the province level. This gets round two problems associated with the VLSS community-level data. First, they were collected only in rural and peri-urban areas. Second, like all community-level data, they may well miss out some potentially important community-level influences on the enrollment decision. For example, Behrman and Knowles (1999) find the premium to be a factor influencing enrollment by students in VHI. It is known that the premium for voluntary enrollment varies geographically in Vietnam (World Bank et al. 2001), but the VLSS provides no information on this variation. Similarly, Jowett (2003) finds that informal risk-sharing networks influence the uptake of VHI, but the VLSS provides no information on their existence. The province-level fixed effects vary considerably, the null hypothesis of common effects being decisively rejected.

\section{Table 3: Enrollment propensity score estimation results}

\begin{tabular}{lcccc}
\hline Covariate & Mean & Std Dev. & Coef. & z-statistic \\
\hline & & & & \\
Primary school & 0.234 & 0.423 & 0.0441 & 0.84 \\
Lower secondary school & 0.472 & 0.499 & 0.2442 & 5.00 \\
Upper seconday school & 0.089 & 0.284 & 0.3209 & 5.42 \\
Post-secondary school & 0.094 & 0.292 & 0.7058 & 12.21 \\
Age in years & 25.373 & 19.905 & 0.0008 & 0.96 \\
Currently in school & 0.254 & 0.435 & 0.4098 & 12.89 \\
Employer in main job is communist party, government or army & 0.016 & 0.126 & 1.7935 & 19.55 \\
Employer in main job is social organization & 0.002 & 0.044 & 1.7481 & 7.04 \\
Employer in main job is state-owned company & 0.013 & 0.113 & 1.3885 & 14.82 \\
Employer in main job is joint venture with foreign partner & 0.000 & 0.021 & 0.2520 & 0.42 \\
Employer in main job is cooperative & 0.006 & 0.075 & 0.4152 & 2.98 \\
Employer in main job is private company or household & 0.049 & 0.215 & -0.4517 & -5.90 \\
Employer in second job is communist party, government or army & 0.002 & 0.043 & 0.8068 & 3.12 \\
Employer in second job is social organization & 0.000 & 0.011 & -0.3994 & -0.27 \\
Employer in second job is state-owned company & 0.000 & 0.018 & 0.3002 & 0.49 \\
Employer in second job is cooperative & 0.002 & 0.050 & 0.0043 & 0.02 \\
Employer in second job is private company or household & 0.009 & 0.096 & -0.5056 & -3.11 \\
Pensioner & 0.032 & 0.176 & 0.5197 & 7.50 \\
Per capita household income & 1914 & 2725 & 0.0000 & 3.14 \\
& & & & \\
\hline
\end{tabular}

Note: Chi squared for province fixed effects: 1140 with $72 \mathrm{df}$.

Figure 1 and Table 4 provide some descriptive statistics of the propensity scores. Prior to matching the distributions of the insured and uninsured differed markedly with respect to the estimated propensity score. ${ }^{9}$ Table 4 shows that contrary to the impression given by Figure 1 ,

\footnotetext{
9 The distributions shown here are for the sample used in the analysis of the impact of VHI on the probability of being inpatient during the previous 12 months.
} 
there are some uninsured with propensity scores larger than 0.75. After nearest-neighbor matching (NNM), the distributions look markedly similar. The difference can be reduced still further (Table 4) by imposing a 0.001 'caliper' (requiring that the squared difference in predicted odds ratios between the nearest neighbors be smaller than 0.001) and imposition of a common support (dropping insured individuals whose propensity score is higher than the maximum or less than the minimum score of the matched uninsured). But in so doing, 214 cases are lost, and the results - unsurprisingly given how similar the distributions are after NNM - turned out to be not markedly different. The results that follow are based on simple NNM.

Fig 1: Histograms of propensity scores of uninsured and insured before and after matching
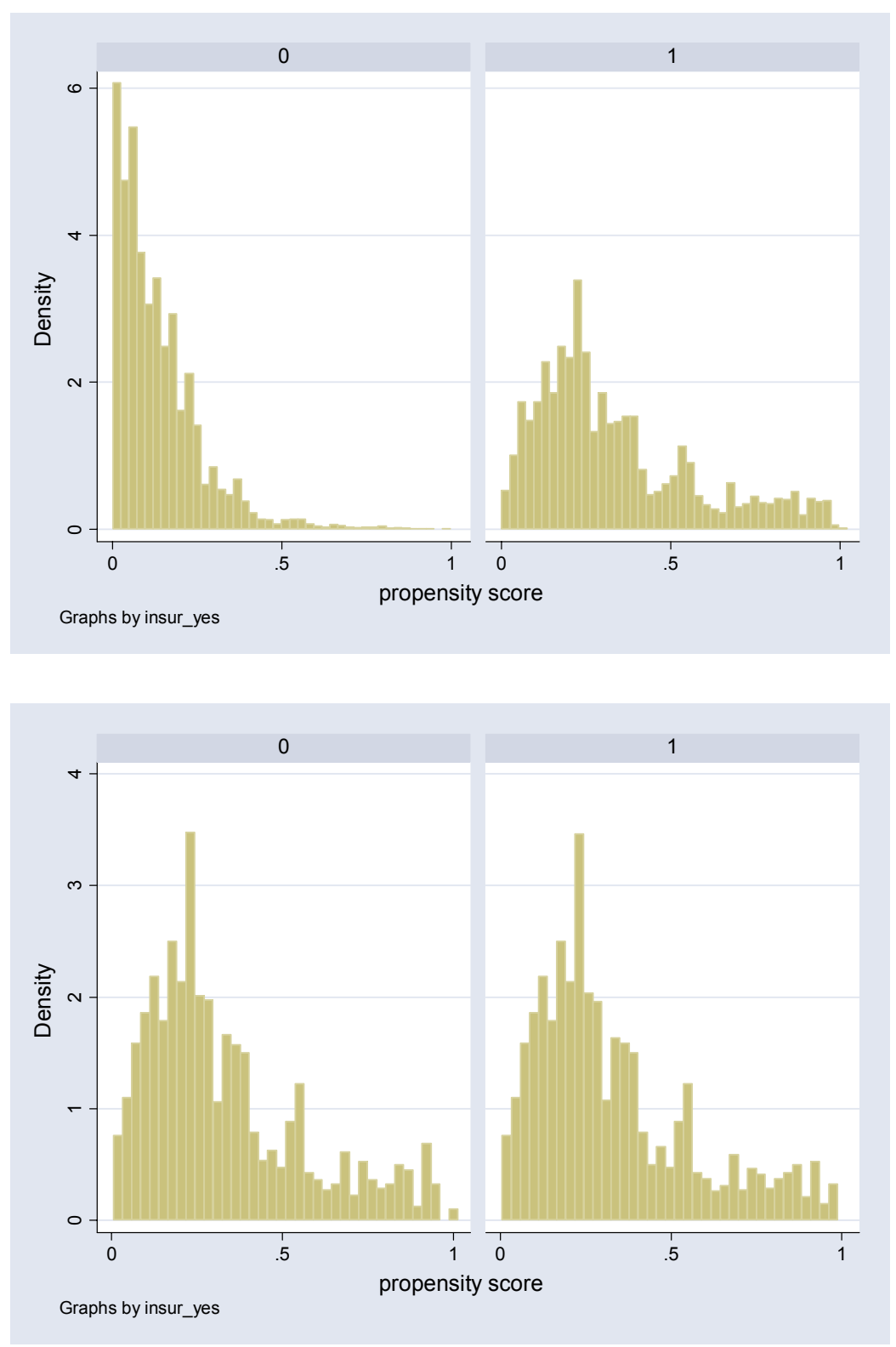


\section{Table 4: Distributions of propensity scores before and after matching}

\begin{tabular}{|c|c|c|c|c|c|c|}
\hline & & $\#$ cases & Mean & Std. Dev. & Min & Max \\
\hline \multirow[t]{2}{*}{ Before matching } & Uninsured & 14795 & 0.135738 & 0.124385 & 0.000453 & 0.988689 \\
\hline & Insured & 3014 & 0.332719 & 0.233047 & 0.004923 & 0.996576 \\
\hline \multirow[t]{2}{*}{ After nearest neighbor matching } & Uninsured & 3011 & 0.331963 & 0.231969 & 0.004934 & 0.988689 \\
\hline & Insured & 3011 & 0.332058 & 0.232220 & 0.004923 & 0.988621 \\
\hline \multirow{2}{*}{$\begin{array}{l}\text { After matching on common support } \\
\text { and with } 0.001 \text { caliper }\end{array}$} & Uninsured & 2797 & 0.295473 & 0.194748 & 0.004934 & 0.988689 \\
\hline & Insured & 2797 & 0.295474 & 0.194748 & 0.004923 & 0.988621 \\
\hline
\end{tabular}

\section{HEALTH OUTCOMES}

We measure health outcomes through anthropometry, there being no data in the VLSS on activities of daily living or self-assessed health. The VLSS is unusual among living standards measurement surveys in recording the height and weight for everyone in the sample, not just children under the age of five (Alderman 2000). Furthermore, anthropometric measurements were taken for the full sample in both waves of the VLSS.

For children, we use z-scores for both height-for-age (HAZ) and weight-for age (WAZ). ${ }^{10}$ Higher z-scores indicate improved nutritional status, and children with values below -2 (i.e. less than two standard deviations below the mean of the reference group) are by convention classified as "underweight" (WAZ) or "stunted" (HAZ). We present results for three age groups: children aged between zero and 4 inclusive in 1992/93 and therefore between 5 and 9 at the time of the second wave; children aged between 5 and 23 in 1992/93; and all children between the ages of zero and 23 in 1992/93. In the second and third cases, in addition to matching on the propensity score, we match on the child's age bracket (the brackets being in five-yearly intervals). ${ }^{11}$

Table 5 shows the results. ${ }^{12}$ VHI produces a significant effect on the height and weight of young children (children aged between 0 and 4 in 1992/93) but not of older children. In the case of weight-for-age but not height-for-age, the effect rises with per capita household consumption; indeed, there is no evidence of any beneficial effect of VHI on weight-for-age among the poorest quintile.

\footnotetext{
${ }^{10}$ We standardize the anthropometric data using the 1990 British growth reference data (Cole, Freeman and Preece 1998) which are available for newborns up to the age of 23. A convenient Stata routine http://www.stata-journal.com/software/sj41/dm0004/zanthro.hlp: is available to undertake these and the more familiar US reference standardizations (Kuczmarski et al. 2000). The latter are available for young people only up to the age of 20.

11 Similar results were obtained when we matched on the propensity score and restricted matches to the same age group. ${ }^{12}$ The treatment effects reported throughout are the average treatment on the treated. The standard errors underlying the $\mathrm{z}-$ statistics were computed treating propensity score as fixed using the Stata add-in 'nnmatch', and requesting the standard error relevant to the population rather than the sample. The reported z-statistics tend to be marginally larger than those obtained via bootstrapping with the Stata add-in 'psmatch2'. This allows for the fact that the propensity score is itself subject to sampling variability but adds substantially to computation time. The F-tests for the constancy of treatment effects across per capita consumption quintiles are obtained from regressions of estimated treatment effects on consumption quintile dummies. The regressions are estimated on a sample comprising insured individuals and matched uninsured individuals. The latter weighted by the number of times they are used as a match for an insured individual. Quintile-specific treatment effects and their standard errors are obtained from this regression.
} 
Table 5: Double-difference estimates of VHI impact on child anthropometrics

\begin{tabular}{|c|c|c|c|c|c|c|}
\hline Outcome & $\begin{array}{l}\text { Age in } \\
1992 / 93\end{array}$ & $\begin{array}{c}\text { Per capita } \\
\text { consumption } \\
\text { quintile in } \\
1992 / 93\end{array}$ & $\begin{array}{c}\text { Treatment } \\
\text { effects }\end{array}$ & z-stat & $\begin{array}{l}\text { F-test consumption } \\
\text { quintile differences }\end{array}$ & Prob $>$ F \\
\hline \multirow[t]{3}{*}{ Height-for-age } & $0-23$ & all & 0.154 & 3.34 & & \\
\hline & $0-4$ & all & 0.456 & 4.06 & $F(4,414)=0.80$ & 0.527 \\
\hline & $5-23$ & all & 0.031 & 0.69 & $\mathrm{~F}(4,1029)=0.51$ & 0.727 \\
\hline \multirow[t]{8}{*}{ Weight-for-age } & $0-23$ & all & 0.113 & 2.58 & & \\
\hline & $0-4$ & all & 0.332 & 3.57 & $F(4,416)=3.70$ & 0.006 \\
\hline & $0-4$ & 1 & -0.115 & -0.61 & & \\
\hline & $0-4$ & 2 & 0.293 & 1.69 & & \\
\hline & $0-4$ & 3 & 0.236 & 1.42 & & \\
\hline & $0-4$ & 4 & 0.348 & 2.03 & & \\
\hline & $0-4$ & 5 & 0.869 & 4.82 & & \\
\hline & $5-23$ & all & 0.023 & 0.49 & $\mathrm{~F}(4,1027)=0.84$ & 0.499 \\
\hline
\end{tabular}

The impacts for under-five children are statistically significant, but are they large enough to matter? The estimated treatment effects translate into increases in height and weight of 2.35 $\mathrm{cm}$ and $0.75 \mathrm{~kg}$ respectively, equivalent to increases on the counterfactual 1997/98 height and weight respectively of $2 \%$ and $4 \%$. Assuming the effects occurred continuously throughout the five years following the 1992/93 survey, these effects are equivalent to an extra $0.47 \mathrm{~cm}$ extra height and $0.15 \mathrm{~kg}$ extra weight per year. To express the effects another way, the annualized VHI impacts are equivalent to $7 \%$ and $9 \%$ of counterfactual annual growth of height and weight, while the total cumulative impacts are equivalent to $37 \%$ and $46 \%$ of annual growth of height and weight..$^{13}$

How do these impacts compare to those reported for other programs? Behrman and Hoddinott (2000) estimate that young children within Mexico's PROGRESA program grew by an additional centimeter in the year following the program's introduction, equivalent to $17 \%$ of the counterfactual mean growth per year, a little over twice that achieved by VHI. Case (2002) estimates that five years after its introduction South Africa's pension scheme had caused a 3-4 $\mathrm{cm}$ increase in height among Colored and Black children aged 0-6. This (cumulative) impact was equivalent to $44 \%$ of a year's growth, a little more than VHI's cumulative impact after a similar period of $37 \%$. South Africa's pension is estimated to have increased weight among young children as well, but only among Colored children. The estimated $1 \mathrm{~kg}$ cumulative impact for this group is a little larger than the $0.75 \mathrm{~kg}$ VHI estimated cumulative impact. Chaudhuri (2003) has estimated that Bangladesh's maternal and child health program increased heights and weights of children under the age of 14 by 0.07 and 0.06 standard deviations respectively. Mackintosh et al. (2002) estimate that a Save-the Children integrated nutrition project in northern Vietnam increased weight-for-age by 0.63 standard deviations, but had no effect on height-forage. Of course, a fully-fledged comparison across these programs would want to take into

\footnotetext{
${ }^{13}$ Among the uninsured, the annual change in height and weight among under-five children between 1992/93 and 1997/98 was $6.4 \mathrm{~cm}$ and $1.6 \mathrm{~kg}$.
} 
account the costs and the other achievements of the programs. With the exception of the Savethe-Children project, the programs are geared toward achieving goals beyond the improvement of the nutritional status of young children, and their budgets reflect this. In 1999, Mexico spent $0.2 \%$ of its GDP on PROGRESA ${ }^{14}$, and in 1995/96 South Africa spent $1.5 \%$ of its GDP on its old-age pension program (Alderman 1999). Vietnam also spent around $0.2 \%$ of its GDP on VHI in 1998, though only $10 \%$ of the budget was associated with revenues in respect of the voluntarily enrolled (Government of Vietnam 2002a).

For adults (defined here as people aged 18 or over in 1992-93), we measure health or nutritional status using the body mass index (BMI), defined as equal to a person's weight in kilograms divided by their height in square meters. A person with a BMI score below 18.5 is considered 'underweight', while someone with a BMI score in the range 18.5-24.9 is considered 'normal'. Someone with a BMI score in the range 25-29.9 is considered to be 'overweight', and someone with a score higher than 30 is considered obese. In Vietnam in the survey period, less than $1 \%$ of the sample in either year was classified as overweight or obese, while roughly one quarter of the sample were classified as underweight. While primarily a measure of nutritional status, BMI has been found to be a good predictor of mortality (Calle et al. 1999). Recent research has shown that leanness-a BMI score in the 'underweight' range-increases the risk of death from a number of causes. ${ }^{15}$

The results in Table 6 suggest that VHI had a significant impact the BMI of adults. The impact rises monotonically with per capita household consumption, and as with weight-for-age among young children, there is no evidence of any beneficial effect of VHI on nutritional status among the poorest quintile (indeed there is a statistically significant negative estimated treatment effect). The estimated treatment effect of 0.303 is equal to $1.5 \%$ of the average 1998 BMI score of the matched uninsured group. Unfortunately it is not possible to say whether this is large or small relative to other programs. While BMI has been used extensively in the medical literature, it has not been widely used in the economics literature ${ }^{16}$ and not at all apparently in the evaluation of programs.

\footnotetext{
14 See http://www.ifpri.org/themes/progresa.htm.

15 A number of recent studies have concluded as much (see e.g. Kark et al. 1995, Seidell et al. 1996, Yuan et al. 1998, Gilmore 1999, Franceschi et al. 2001, Gallus et al. 2001, Marret et al. 2001, Qian, Guo and Zhang 2001, Muller et al. 2003, Thorogood et al. 2003, Zhang et al. 2003, Inoue, Sobue and Tsugane 2004).

16 The studies to date have typically used BMI as a measure of adult nutrition as a factor influencing child nutrition (Alderman 2000).
} 
Table 6: Double-difference estimates of VHI impact on adult BMI

\begin{tabular}{|c|c|c|c|c|c|}
\hline $\begin{array}{c}\text { Age in } \\
1992 / 93\end{array}$ & $\begin{array}{c}\text { Per capita } \\
\text { consumption } \\
\text { quintile in } \\
1992 / 93\end{array}$ & $\begin{array}{l}\text { Treatment } \\
\text { effects }\end{array}$ & z-stat & $\begin{array}{l}\text { F-test consumption } \\
\text { quintile differences }\end{array}$ & Prob $>F$ \\
\hline $18+$ & all & 0.303 & 2.91 & $F(4,1358)=6.18$ & 0.000 \\
\hline $18+$ & 1 & -0.425 & -2.02 & & \\
\hline $18+$ & 2 & 0.049 & 0.26 & & \\
\hline $18+$ & 3 & 0.302 & 2.09 & & \\
\hline $18+$ & 4 & 0.168 & 1.31 & & \\
\hline $18+$ & 5 & 0.617 & 6.15 & & \\
\hline
\end{tabular}

\section{HEALTH SERVICE UTILIZATION}

An obvious channel through which VHI impacts on nutritional status is increased use of health care. Using the VLSS panel to investigate this possibility is not straightforward because the wording of the health utilization questions changed significantly from one wave to the next. We adopt two approaches: in the first, we use the panel and do the best with what is available; in the second, we focus on the 1998 wave and estimate VHI impacts via single-difference matching (i.e. comparing levels of utilization of the insured and matched uninsured, rather than changes in them).

In the 1992/93 VLSS, respondents who reported illness or injury during the previous 4 weeks were then asked whether a contact with any health service provider had occurred during the same period. Examples of different types of provider were read out, but they were simply examples. Respondents were then asked who the first contact was with, but they were not asked whether there were any further contacts with the same provider or with any other provider. In the second wave, all respondents - whether or not they had reported any recent sickness in a preceding question - were taken through a closed list of different types of provider, and asked in each case whether a contact had occurred in the previous 4 weeks, and if so how many times the provider in question had been consulted. The different approaches in the two years make comparisons across years difficult, but what can be done is to construct a variable in both waves indicating whether someone reporting sickness made a contact with any provider (World Bank et al. 2001).

The results in Table 7 suggest that VHI increased the probability of a sick person contacting a provider among the sample as a whole and for individuals aged five and over, but not for children under the age of five. These results are of course limited by the limited usefulness of the utilization variable. It does not capture the number of visits, simply the probability. It excludes preventive visits, quite possibly a route via which VHI coverage translates into better outcomes for younger children. And there is the possibility that in 1997/98 some visits were inadvertently omitted because of the closed list of provider types. The list is extensive, but it does not include explicitly any visits to a school clinic. Given the fact that VHI 
has helped establish such school clinics, and given the apparent effects that VHI has had on anthropometric measures of health status among younger children, this is a cause for concern.

Table 7: Double-difference estimates of VHI impact on contact probability among sick

\begin{tabular}{ccccc}
\hline $\begin{array}{c}\text { Age in } \\
1992 / 93\end{array}$ & $\begin{array}{c}\text { Treatment } \\
\text { effects }\end{array}$ & z-stat & $\begin{array}{c}\text { F-test consumption } \\
\text { quintile differences }\end{array}$ & Prob $>$ F \\
\hline & & & & \\
$0-4$ & 0.0389 & 0.95 & $\mathrm{~F}(4,432)=2.28$ & 0.060 \\
$5+$ & 0.0473 & 3.41 & & \\
All & 0.0433 & 3.38 & & \\
& & & & \\
\hline
\end{tabular}

We can get richer utilization information by focusing on the 1997-98 survey. In so doing, we are forced to use the single-difference matching estimator, and are therefore unable to eliminate any biases introduced by selection on time-invariant unobservables as we were able to with the double-difference approach. Table 8 reports results separately for under-fives and individuals over the age of five. For both age groups, VHI appears to stimulate use of commune health centers $(\mathrm{CHCs})$. Among the under-fives, VHI appears also to encourage visits to pharmacists to obtain prescription medicines, and to reduce visits to pharmacists to obtain advice and non-prescribed medicines. Among individuals aged five and over, but not among young children, VHI encourages the use of hospital care-including inpatient care-and to a much lesser extent the use of polyclinics. With the exception of visits to CHCs, impacts do not differ significantly across the consumption distribution; VHI only has a significant impact on the use of CHCs among the poor. These results are broadly similar to those reported by Trivedi (2003), though he did not report separate results for children and adults, or for the two different types of pharmacy visit. He also found VHI increased utilization of $\mathrm{CHC}$ and hospital care, and decreased pharmacy visits overall. However, unlike us, he found VHI caused substitution away from the private sector. 
Table 8: Double-difference estimates of VHI impact on contact probability among sick

\begin{tabular}{lcccc}
\hline Outcome & $\begin{array}{c}\text { Treatment } \\
\text { effects }\end{array}$ & z-stat & $\begin{array}{c}\text { F-test consumption } \\
\text { quintile differences }\end{array}$ & Prob > F \\
\hline Age 0-4 in 1992/93 & & & & \\
Hospital visits & & & & \\
CHC visits & 0.0000 & 0.00 & $\mathrm{~F}(4,432)=0.60$ & 0.66 \\
Polyclinic visits & 0.0297 & 1.73 & $\mathrm{~F}(4,432)=2.31$ & 0.06 \\
Private provider visits & 0.0000 & 0.00 & $\mathrm{~F}(4,432)=1.75$ & 0.14 \\
Pharmacist visits for prescribed medicines & 0.0115 & 0.36 & $\mathrm{~F}(4,432)=0.79$ & 0.53 \\
Pharmacist visits for advice \& nonprescribed medicines & -0.0252 & 1.81 & $\mathrm{~F}(4,432)=2.00$ & 0.09 \\
Visit to traditional healer & 0.0000 & -1.69 & $\mathrm{~F}(4,432)=0.57$ & 0.69 \\
Total visits & -0.1830 & -1.31 & $\mathrm{~F}(4,432)=0.44$ & 0.78 \\
Inpatient spell during 1997/98 & 0.0160 & 0.93 & $\mathrm{~F}(4,432)=0.39$ & 0.82 \\
& & & & 0.69 \\
Age 5+ in 1992/93 & & & & \\
Hospital visits & 0.0753 & 6.54 & $\mathrm{~F}(4,2572)=1.01$ & 0.40 \\
CHC visits & 0.0211 & 2.13 & $\mathrm{~F}(4,2572)=5.27$ & 0.00 \\
Polyclinic visits & 0.0085 & 3.15 & $\mathrm{~F}(4,2572)=1.06$ & 0.38 \\
Private provider visits & -0.0089 & -0.35 & $\mathrm{~F}(4,2572)=0.83$ & 0.51 \\
Pharmacist visits for prescribed medicines & -0.0008 & -0.06 & $\mathrm{~F}(4,2571)=1.87$ & 0.11 \\
Pharmacist visits for advice \& nonprescribed medicines & -0.0237 & -0.61 & $\mathrm{~F}(4,2571)=0.20$ & 0.94 \\
Visit to traditional healer & 0.0008 & 0.12 & $\mathrm{~F}(4,2572)=0.38$ & 0.82 \\
Total visits & 0.0472 & 0.82 & $\mathrm{~F}(4,2571)=0.93$ & 0.45 \\
Inpatient spell during 1997/98 & 0.0621 & 8.53 & $\mathrm{~F}(4,2572)=0.59$ & 0.67 \\
& & & & \\
\hline
\end{tabular}

These patterns do not seem inconsistent with the health status impacts of VHI. Many key interventions for young children-including vaccinations, vitamin supplements as well as the giving of advice on nutrition, hygiene and other home-delivered interventions such as oral rehydration therapy - can easily be delivered in a primary care setting (Bryce et al. 2003, Jones et al. 2003). Furthermore, Vietnam's primary care providers scored well in a recent international study in terms of correctly diagnosing and treatment common childhood illnesses (World Health Organization 1998). Medicines - especially antibiotics - have a role to play in treating pneumonia, dysentery and other childhood illnesses, and while "irrational" drug use is known to be a problem even among professional providers, it seems likely that this problem and the problem of counterfeit drugs is greater among drug vendors. It therefore seems likely that in a country like Vietnam child health can only improve if mothers switch from using pharmacists as providers of advice to using them as suppliers of prescribed drugs. The large impacts on hospital use among older children and adults also seem consistent with the health impacts earlier. In the case of adults - in contrast to the case of young children - it seems likely that if the estimated BMI impacts derive from additional use of medical care, some additional use of hospital care would likely be involved. 


\section{OUT-OF-POCKET PAYMENTS}

VHI need not necessarily cause out-of-pocket payments to fall. If the demand for health care covered by VHI is especially elastic with respect to price, or if the demand for health care generally is especially sensitive to the reduction of risk and uncertainty, VHI could conceivably result in higher out-of-pocket payments.

Both surveys contain estimates for the previous twelve months of cash and in-kind payments for health care. These data are collected from all respondents, whether or not they had been ill in the previous 4 weeks. In addition, the 1997/98 survey allows a reliable estimate to be made of out-of-pocket spending in the 4 weeks prior to the interview ${ }^{17}$, and permits annual health spending to be broken down into inpatient and other health spending. The numbers are in thousands of Vietnamese dong. The double-difference estimate of annual out-of-pocket spending is negative and significant (Table 9), in contrast to the single-difference estimate for 4week and annual total out-of-pocket spending derived from the 1997/98 data alone. The last two lines of Table 9 point to VHI increasing - albeit not significantly-inpatient care spending, and having a dampening effect on spending on other types of care.

Table 9: Estimates of VHI impact on out-of-pocket health spending

\begin{tabular}{lcc}
\hline & $\begin{array}{c}\text { Treatment } \\
\text { effect }\end{array}$ & Z-stat \\
\hline & & \\
Double difference on longitudinal data & & \\
Change in out-of-pocket spending between 1992/93 and 1997/98 & -51.967 & -2.52 \\
& & \\
Single difference on 1997/98 data & & -0.27 \\
Out-of-pocket spending in last 4 weeks & -2.530 & -0.96 \\
Out-of-pocket spending in 1997/98 & -18.744 & 1.08 \\
Inpatient expenditure in 1997/98 & 8.636 & -1.67 \\
Non-inpatient out-of-pocket spending 1997/98 & -27.380 & \\
\hline
\end{tabular}

Jowett et al. (2003) also found that VHI reduced out-of-pocket payments, though there are some differences between their study and ours are worth noting: their survey was not nationally representative; VHI coverage was restricted to voluntary coverage (their data were collected in the city of Hai Phong that succeeded for a while in enrolling adults as well as school children in the voluntary scheme); out-of-pocket payment data were collected only from those reporting illness; and their results refer only to those reporting positive payments. Trivedi (2003) found some evidence from the 1997/98 data of VHI increasing out-of-pocket expenditures ${ }^{18}$, but the effect was not significant when commune fixed effects were included in the regression model.

\footnotetext{
17 The 1992/93 survey also asked about spending in the previous 4 weeks, but only of those reporting illness and only in respect of first visits to each provider type.

18 Spending was defined in Trivedi's analysis as spending over the past 4 weeks plus spending over the past 12 months.
} 


\section{NONMEDICAL CONSUMPTION}

VHI may also have an impact on nonmedical consumption by reducing the uncertainty associated with future medical expenses, encouraging households to reduce savings. Some items of nonmedical consumption - such as food consumption, and expenditures on water and sanitation - may have effects on health outcomes, especially among children.

We examine the impacts of VHI on aggregate per capita household nonmedical consumption, as well as its impact on various sub-aggregates of household consumption, including food consumption, and expenditures on electricity, water, garbage collection and water. Aggregate consumption includes the imputed use value associated with ownership of consumer durables and other assets, and as is standard in LSMS surveys, consumption includes expenditures on services, as well as the value of home-produced food (Glewwe, Gragnolati and Zaman 2000). The focus on per capita household consumption makes sense if households share resources, so that health insurance coverage of one household member reduces the financial risk faced by all household members. Clearly, the risk faced by the household is reduced by more if several household members are insured, rather than just one member. We therefore experimented with three different methods of health insurance coverage at the household level. The first was to classify a household as insured if every member is insured. However, since less than $4 \%$ of households fall into this category, this approach was rejected. The second was to define a household as insured if the majority of household members are insured. The third was to define a household as insured if at least one member is insured.

The double-difference results in Table 10 suggest that VHI coverage increases nonmedical consumption. The impact is larger in the case where coverage is defined as the majority of members being covered than in the case where coverage is defined as one or more members being covered. Whichever definition of coverage is used, the effect on nonmedical consumption is larger in absolute size than the effect on medical consumption (the latter is not significantly different from zero at the household level). This result is not implausible. A riskaverse household without health insurance and without access to capital markets could quite reasonably set aside more than the expected value of per capita household medical outlays. In 1997/98, mean per capita household out-of-pocket spending on health care was equal to around 100 (thousand dong), with a standard deviation of 305, and a maximum of 8500 . The nonmedical consumption effects in Table 10 are less than the mean plus one standard deviation. VHI has a bigger impact on non-food consumption than on food consumption, the latter effect in both specifications being significant only among the poorest quintile. The different specifications yield somewhat different results for the individual components of aggregate consumption, though in both a significant impact on education expenditures emerges. The 1997/98 questionnaire explicitly asks that VHI premiums be excluded from education expenses, but it seems possible that this was not internalized by the enumerators. The treatment effect for education expenditures among the subset of households with a child in school is broadly similar (59.33 and a z-stat of 3.09 in the case where a household is defined as being covered if it has a majority with health insurance), suggesting that the effect does not reflect health insurance picking up the effects of being in school. Overall, the treatment effects suggest VHI may have had some positive impact on several items of household consumption that may have a beneficial effect on health, notably food consumption, garbage disposal and education expenditures, and investment in household durables. 
Table 10: Double-difference estimates of VHI impact on components of
per capita nonmedical household consumption

\begin{tabular}{|c|c|c|c|c|}
\hline & $\begin{array}{l}\text { Treatment } \\
\text { effect }\end{array}$ & z-stat & $\begin{array}{c}\text { F-test } \\
\text { consumption } \\
\text { quintile } \\
\text { differences: } \\
\text { Prob > F }\end{array}$ & $\begin{array}{c}\text { Quintiles } \\
\text { with } \\
\text { significant } \\
\text { effects } \\
\text { where } \\
\text { significant } \\
\text { differences } \\
\text { exist }\end{array}$ \\
\hline \multicolumn{5}{|c|}{ Majority of household members insured } \\
\hline Medical consumption & -28.898 & -0.92 & 0.0847 & \\
\hline Nonmedical consumption & 319.728 & 4.20 & 0.5848 & \\
\hline Food consumption & 77.150 & 2.40 & 0.0002 & Bottom \\
\hline Total nonfood consumption & 179.103 & 3.61 & 0.8064 & \\
\hline Garbage collection expenditures & 0.774 & 2.68 & 0.0108 & Top \\
\hline Water expenditures & 1.454 & 0.93 & 0.0837 & \\
\hline Electricity expenditures & 5.490 & 1.34 & 0.6330 & \\
\hline Education expenditures & 42.357 & 2.84 & 0.2874 & \\
\hline Imputed rent expenditures & 3.030 & 0.19 & 0.4443 & \\
\hline Other non-food expenditures & 29.791 & 0.87 & 0.9347 & \\
\hline Use value of durables & 86.962 & 3.31 & 0.6749 & \\
\hline \multicolumn{5}{|c|}{ At least one household member insured } \\
\hline Medical consumption & -34.793 & -1.35 & 0.7917 & \\
\hline Nonmedical consumption & 229.767 & 3.52 & 0.5973 & \\
\hline Food consumption & 9.972 & 0.40 & 0.0000 & Bottom \\
\hline Total nonfood consumption & 175.541 & 3.64 & 0.4876 & \\
\hline Garbage collection expenditures & 0.247 & 0.97 & 0.0001 & Top \\
\hline Water expenditures & 2.103 & 1.48 & 0.0000 & Top \\
\hline Electricity expenditures & 2.599 & 0.74 & 0.0000 & Top \\
\hline Education expenditures & 55.872 & 3.27 & 0.0000 & $4^{\text {th }}$, Top \\
\hline Imputed rent expenditures & 11.866 & 1.28 & 0.5324 & \\
\hline Other non-food expenditures & 78.532 & 2.55 & 0.0412 & Bottom \\
\hline Use value of durables & 36.057 & 1.65 & 0.8604 & \\
\hline
\end{tabular}

\section{CONCLUSIONS}

The results in this paper lend support to recent research that argues that health insurance can improve health outcomes and can expand household consumption through the reduction of financial risk. The use of panel data collected before and after the insurance program's introduction allows us to eliminate any confounding effects due to selection on time-invariant unobservables, and our coupling of propensity score matching with a double-difference estimator allows us to reduce the risk of biases due to inappropriate specification of the outcome regression model. The fact remains, however, that insurance was not assigned randomly, and there remains the possibility that people may have been selected into the program in part on the basis of timevarying unobservables. It is possible, in other words, that those in the program did not share the 
same time trend in unobservables as those outside the program. This is always a risk in a nonexperimental study, including quasi-experimental designs where insurance is rolled out at a different pace across geographic areas, rather than as here across different occupational groups.

Subject to this caveat, our results suggest that Vietnam's health insurance program impacted favorably on height-for-age and weight-for-age of young schoolchildren, with a treatment effect in the case of height-for-age that is not much smaller than that estimated for Mexico's PROGRESA program (Behrman and Hoddinott 2000) and South Africa's very generous old-age pension program (Case 2001). Among adults too we also find a significant impact of VHI on our anthropometric outcome (BMI). Our results suggest that among young children, VHI increases use of primary care facilities, and leads to a substitution away from the use of pharmacists as a source of advice and non-prescribed medicines toward the use of them as a supplier of medicines prescribed by a health professional. Among older children an adults, VHI results in a marked increase in the use of hospital inpatient and outpatient departments.

Our results also suggest that VHI causes a reduction in annual out-of-pocket expenditures on health, and an increase in nonmedical household consumption, including food consumption, and various items of non-food consumption, including education spending and investment in household durables. Our estimate of the VHI-induced reduction in out-of-pocket health spending is considerably smaller than our estimate of the VHI-induced increase in nonmedical consumption. This is consistent with the idea that households hold back their household consumption considerably if, through lack of health insurance, they are exposed to the risk of large out-of-pocket expenditures. This is especially plausible in a country where at the time (1993), a single visit to a public hospital cost on average the equivalent of $20 \%$ of a person's annual non-food consumption (World Bank et al. 2001). 


\section{References}

Alderman, H. (1999). Safety Nets and Income Transfers in South Africa. Washington DC, World Bank. South Africa Poverty and Inequality Discussion Paper 19335.

Alderman, H. (2000). Anthropometry. Designing Household Survey Questionnaires for Developing Countries. P. Glewwe. Washington DC, The World Bank. 1: 251-272.

Arrow, K. (1963). "Uncertainty and the Welfare Economics of Medical Care." American Economic Review 53: 941-73.

Behrman, J. and J. Knowles (1999). The demand for health insurance in Vietnam. Mimeo.

Behrman, J. R. and J. Hoddinott (2000). An Evaluation of the Impact of PROGRESA on Preschool Child Height. Washington, D.C., International Food Policy Research Institute.

Bloom, G. (1998). "Primary health care meets the market in China and Vietnam." Health Policy 44(3): 233-52.

Blundell, R. and M. Costa Dias (2000). "Evaluation methods for non-experimental data." Fiscal Studies 21(4): 427-68.

Bryce, J., et al. (2003). "Reducing child mortality: can public health deliver?" The Lancet 362(9378): 159-164.

Calle, E. E., et al. (1999). "Body-mass index and mortality in a prospective cohort of U.S. adults." N Engl J Med 341(15): 1097-105.

Case, A. (2001). Health, income, and economic development. Annual World Bank Conference on Development Economics. Washington DC, World Bank.

Case, A. (2002). Health, Income and Economic Development. Annual World Bank Conference on Development Economics: 2001/2002. B. Pleskovic and N. Stern. Washington, D.C., World Bank; Oxford and New York: Oxford University Press: v, 269.

Chaudhuri, A. (2003). Program impact on the health and nutritional status of children: evidence from rural Bangladesh, University of Washington. Mimeo.

Chou, S.-Y., J.-T. Liu and J. K. Hammitt (2003). "National Health Insurance and Precautionary Saving: Evidence from Taiwan." Journal of Public Economics 87(9-10): 1873-94.

Chou, Y. J. and D. Staiger (2001). "Health insurance and female labor supply in Taiwan." J Health Econ 20(2): 187-211.

Cole, T. J., J. V. Freeman and M. A. Preece (1998). "British 1990 growth reference centiles for weight, height, body mass index and head circumference fitted by maximum penalized likelihood." Stat Med 17(4): 407-29. 
Currie, J. and J. Gruber (1996a). "Health Insurance Eligibility, Utilization of Medical Care, and Child Health." Quarterly Journal of Economics 111(2): 431-66.

Currie, J. and J. Gruber (1996b). "Saving Babies: The Efficacy and Cost of Recent Changes in the Medicaid Eligibility of Pregnant Women." Journal of Political Economy 104(6): 1263-96.

Currie, J. and J. Gruber (1997). The Technology of Birth: Health Insurance, Medical Interventions, and Infant Health, National Bureau of Economic Research Working Paper: 5985: 41.

Cutler, D. and R. Zeckhauser (2000). The anatomy of health insurance. Handbook of Health Economics. A. Culyer and J. Newhouse. Amserdam, Elsevier. 1A: 409-460.

de Meza, D. (1983). "Health insurance and the demand for medical care." J Health Econ 2(1): 47-54.

Feldstein, M. S. (1973). "The Welfare Loss of Excess Health Insurance." Journal of Political Economy 81(2): 251-80.

Franceschi, S., et al. (2001). "Leanness as early marker of cancer of the oral cavity and pharynx." Ann Oncol 12(3): 331-6.

Gallus, S., et al. (2001). "Leanness and squamous cell oesophageal cancer." Ann Oncol 12(7): 975-9.

Gilmore, J. (1999). "Body mass index and health." Health Rep 11(1): 31-43(Eng); 33-47(Fre).

Glewwe, P. (2003). An overview of economic growth and household welfare in Vietnam in the 1990s. Economic Growth, Poverty and Household Welfare: Policy Lessons from Vietnam. D. Dollar. Washington DC, World Bank.

Glewwe, P., M. Gragnolati and H. Zaman (2000). Who gained from Vietnam's boom in the 1990s? Washington DC, The World Bank. Policy Research Working Paper \#2275.

Government of Vietnam (2002a). Health Insurance Statistical Yearbook. Hanoi.

Government of Vietnam (2002b). Health Insurance Statistical Yearbook 1993-2002. Ha Noi, Ministry of Labor and Social Security.

Gruber, J. and A. Yelowitz (1999). "Public Health Insurance and Private Savings." Journal of Political Economy 107(6): 1249-74.

Guariglia, A. and M. Rossi (2004). "Private medical insurance and saving: evidence from the British Household Panel Survey." J Health Econ 23(4): 761-83.

Hanratty, M. J. (1996). "Canadian National Health Insurance and Infant Health." American Economic Review 86(1): 276-84. 
Harmon, C. and B. Nolan (2001). "Health insurance and health services utilization in Ireland." Health Econ 10(2): 135-45.

Heckman, J., et al. (1998). "Characterizing Selection Bias Using Experimental Data." Econometrica 66(5): 1017-98.

Heckman, J. J., H. Ichimura and P. E. Todd (1997). "Matching as an Econometric Evaluation Estimator: Evidence from Evaluating a Job Training Programme." Review of Economic Studies 64(4): 605-54.

Imbens, G. W. (2004). "Nonparametric Estimation of Average Treatment Effects under Exogeneity: A Review." Review of Economics and Statistics 86(1): 4-29.

Inoue, M., T. Sobue and S. Tsugane (2004). "Impact of body mass index on the risk of total cancer incidence and mortality among middle-aged Japanese: data from a large-scale population-based cohort study--the JPHC study." Cancer Causes Control 15(7): 671-80.

Jalan, J. and M. Ravallion (2001). Behavioral Responses to Risk in Rural China. Journal of Development Economics. 66: 23-49.

Jalan, J. and M. Ravallion (2003a). "Does Piped Water Reduce Diarrhea for Children in Rural India?" Journal of Econometrics 112(1): 153-73.

Jalan, J. and M. Ravallion (2003b). "Estimating the benefit incidence of an antipoverty program by propensity-score matching." Journal of Business and Economic Statistics 21(1): 1930.

Jones, G., et al. (2003). "How many child deaths can we prevent this year?" Lancet 362(9377): 65-71.

Jowett, M. (2003). "Do informal risk-sharing networks crowd out public voluntary health insurance? Evidence from Vietnam." Applied Economics in press.

Jowett, M., P. Contoyannis and N. D. Vinh (2003). "The impact of public voluntary health insurance on private health expenditures in Vietnam." Soc Sci Med 56(2): 333-42.

Kark, J. D., et al. (1995). "Are lean smokers at increased risk of lung cancer? The Israel Civil Servant Cancer Study." Arch Intern Med 155(22): 2409-16.

Kuczmarski, R. J., et al. (2000). "CDC growth charts: United States." Adv Data(314): 1-27.

Levy, H. and D. Meltzer (2001). What Do We Really Know About Whether Health Insurance Affects Health? Chicago, University of Chicago. Mimeo.

Mackintosh, U. A., D. R. Marsh and D. G. Schroeder (2002). "Sustained positive deviant child care practices and their effects on child growth in Viet Nam." Food Nutr Bull 23(4): 1827. 
Manning, W. G. and M. S. Marquis (1996). "Health insurance: the tradeoff between risk pooling and moral hazard." J Health Econ 15(5): 609-39.

Marret, H., et al. (2001). "Low body mass index is an independent predictive factor of local recurrence after conservative treatment for breast cancer." Breast Cancer Res Treat 66(1): $17-23$.

Muller, H. L., et al. (2003). "Volumetric bone mineral density in patients with childhood craniopharyngioma." Exp Clin Endocrinol Diabetes 111(3): 168-73.

Narayan, D., et al. (2000). Voices of the Poor: Can Anyone Hear Us? New York, N.Y., Oxford University Press.

Newman, J., et al. (2002). "An impact evaluation of education, health and water supply investments of the Bolivian social investment fund." World Bank Economic Review 16(2): 241-274.

Nyman, J. A. (1999). "The value of health insurance: the access motive." J Health Econ 18(2): $141-52$.

Pradhan, M. and L. Rawlings (2002). "The impact and targeting of social infrastructure investments: Lessons from the Nicaraguan Social Fund." World Bank Economic Review 2: $275-295$.

Qian, W., J. Guo and W. Zhang (2001). "[A prospective study on the association between underweight and mortality from all cause]." Zhonghua Yi Xue Za Zhi 81(19): 1162-5.

Ravallion, M., et al. (2003). "What can ex-participants reveal about a program's impact." Journal of Human Resources in press.

Rosenbaum, P. and D. Rubin (1983). "The central role of the propensity score in observational studies for causal effects." Biometrika 70: 41-55.

Saadah, F., M. Pradhan and R. Sparrow (2001). The effectiveness of the Health Card as an instrument to ensure access to medical care for the poor during the crisis. Washington DC, World Bank.

Sapelli, C. and B. Vial (2003). "Self-selection and moral hazard in Chilean health insurance." J Health Econ 22(3): 459-76.

Seidell, J. C., et al. (1996). "Overweight, underweight, and mortality. A prospective study of 48,287 men and women." Arch Intern Med 156(9): 958-63.

Thorogood, M., et al. (2003). "Relation between body mass index and mortality in an unusually slim cohort." J Epidemiol Community Health 57(2): 130-3.

Trivedi, P. (2003). Patterns of health care use in Vietnam: Aanalysis of 1998 Vietnam Living Standards Survey data. Economic Growth, Poverty and Household Welfare: Policy 
Lessons from Vietnam. P. Glewwe, N. Agrawal and D. Dollar. Washington DC, World Bank.

Trujillo, A. J. (2003). "Medical care use and selection in a social health insurance with an equalization fund: evidence from Colombia." Health Econ 12(3): 231-46.

Vera-Hernandez, M. (2003). "Structural Estimation of a Principal-Agent Model: Moral Hazard in Medical Insurance." RAND Journal of Economics 34(4): 670-93.

Wagstaff, A. (2002). "Measuring equity in health care financing: reflections on and alternatives to WHO's fairness of financing index." Health Economics 11(2): 103-115.

Wagstaff, A. and E. van Doorslaer (2003). "Catastrophe and impoverishment in paying for health care: with applications to Vietnam 1993-98." Health Econ in press.

Waters, H. R. (1999). "Measuring the impact of health insurance with a correction for selection bias--a case study of Ecuador." Health Econ 8(5): 473-83.

World Bank (1997). Health, Nutrition and Population Sector Strategy. Washington DC, The World Bank.

World Bank, et al. (2001). Vietnam. Growing Healthy: A Review of Vietnam's Health Sector. Hanoi, The World Bank.

World Health Organization (1998). CHD 1996-97 report. Geneva, World Health Organization.

Yuan, J. M., et al. (1998). "Body weight and mortality: a prospective evaluation in a cohort of middle-aged men in Shanghai, China." Int J Epidemiol 27(5): 824-32.

Zhang, J., et al. (2003). "Effect of body mass index on adenocarcinoma of gastric cardia." World J Gastroenterol 9(12): 2658-61. 